\title{
The title of the thesis in the professional training of the musician. Auxiliary tools
}

\section{El título de la tesis de grado en la formación profesional del músico. Herramientas auxiliares}

\author{
JUAN-CARVAJAL, Mara Lioba $† *$ \\ Universidad Autónoma de Zacatecas \\ ID $1^{\text {st }}$ Author: Mara Lioba, Juan-Carvajal / ORC ID: 0000-0001-6968-3813, Researcher ID Thomson: P-7756-2016, CVU \\ CONACYT ID: 216443
}

DOI: $10.35429 / J T E R .2019 .16 .5 .1 .9$

Received September 02, 2019; Accepted December 30, 2019

\begin{abstract}
One of the most laborious aspects at the beginning of a research process for graduation project into the musician professional training is the title of the thesis. This requirement could not represent much difficulty however, sometimes the rush with which a first vision of the project or research design is made brings into a title proposal that could not satisfy the expectations of the student in the future. The experience in these situations have shown late progress and loose of motivation. The alternatives that could be used in order to prevent this situation are many and can be applied during the professional training, nevertheless at the ending of the studies, time is important and the chores get busy; different tools are offered so the student, professor or adviser can develop the idea of the final project and thesis.
\end{abstract}

Thesis title, Mind map, Concept map, Research portfolio

\begin{abstract}
Resumen
Uno de los aspectos más trabajosos para el inicio del proceso investigativo como parte del proyecto de titulación durante la formación del músico profesional es el enunciado del título de la tesis. Aunque aparenta no presentar mayores dificultades, en ocasiones la premura con que se elabora una primera versión del proyecto, protocolo, o diseño de investigación trae consigo proponer un título que posteriormente no satisface las expectativas del estudiante; la experiencia indica en estos casos la aparición de procesos morosos y la desmotivación. Las alternativas para revertir tal situación son muchas y se aplican en diferentes momentos durante la formación del profesional; sin embargo, en la etapa de culminación de estudios, el tiempo apremia y los procesos se aglomeran; con este fin, se ofrecen herramientas que pueden emplearse en el momento en que estudiante, profesor y tutor, comienzan a generar la idea del proyecto de titulación y de la tesis.
\end{abstract}

Título de tesis, Mapa mental, Mapa conceptual, Portafolio de investigación 


\section{Introduction}

In the curricula for the training of the professional musician of many universities, several variants are considered depending on the final evaluation, among which are the realization of a graduation concert or recital and / or the degree project that culminates with the defense of a thesis or thesis, the latter case, depends on an investigative process.

Although in most of these universities research is considered a transversal axis or institutional curricular strategy, almost always the young musician is not aware of its importance until the moment of writing the thesis arrives; This may be due, among other causes, to the professional profile of the teachers that is generally oriented towards the performance of the music, or to the motivation of the students who prepare throughout the race for the realization of a graduation recital.

In addition to presenting the research as a transversal axis, in the professional profile of the musician, the desire for unity between the educational and the instructional in almost all universities is manifested; in the case of instrumentalists, this indicates the training of high-level performers that can transmit to the public all the perception they have of the composer, the work and the time with sufficient sensitivity to satisfy the generality of tastes and knowledge that are concentrated in An auditorium.

The normative documents for the musician's training explain the achievement of elements such as good tuning, rhythm and agogics, phrasing, sound quality, memory, theoretical, stylistic and aesthetic knowledge, among others, as well as ensuring the physical development and values of the student. Some such as humanism and responsibility are fundamentally revealed to the extent that the future professional faces an audience during instrumental practice in concerts and recitals.

For these reasons, the pedagogical process in music is peculiar, has its roots in cultural traditions, combines individual and collective activities, and focuses on the development of skills. In the curricula there are subjects that require teamwork such as workshops, ensemble subjects or music theory, in them, the figure should not exceed the number of 12 students.
The subject that in general attracts the most attention, for its reason of being as music professionals, is what forms them as instrumentalists, the classes are mostly individualized and the student confronts the teacher with the advances he has made during his preparation individual.

More than a teaching-learning process, the instrument class becomes one of guardianship where differentiated work is placed first, while the teacher, meticulous and detailed, focuses on achieving the best results, taking into account the characteristics and progress of each student, the level they are in, technical knowledge about music, and acquired skills.

Harmonizing all these elements is only possible when research is recognized as a transversal axis during the entire process of professional training, however, although in many cases it is institutionalized, this aspect is neglected, or it is carried out in practice in a systematic way, but empirical, regardless of the rigor that an investigative process entails.

Perhaps this is the reason why in more than $50 \%$ of cases, when the student adopts the option of a degree project, even when the participation of several advisors is present in the analysis and discussion of each case, it is somewhat difficult enunciating a title for the thesis.

To get to shape the degree it is necessary to inquire about the previous preparation that the student has had throughout his career, and to enhance the experience of the advisor, tutor and teacher, in order to guide him towards the search for information on the topics that most interest him ; nevertheless, the inexperience of the student in investigative processes puts in doubt and hinders his first steps. Therefore, this work offers some auxiliary tools that can be used at the moment when the student, together with the teacher and the tutor, begin to generate the idea of the degree project and the thesis. 


\section{Methodological strategy}

The auxiliary tools for the preparation of the students have been used in formative processes of different levels, for this purpose, initially a study was carried out where, fundamentally, the scientific methods were combined: document analysis, unstructured interview - in which considered a coefficient of concordance $(\mathrm{Cc} \geq 80)$ as a community of criteria-, and survey applied to teachers (annex 1) for the assessment of the usefulness of the use of auxiliary tools for the generation of the research design and the statement of the title of the thesis.

With the analysis of documents, those tools that could be used in a first stage were identified in order to project the research and specify the title of the thesis and the study of experiences in its application in other areas of knowledge.

The unstructured interview began with an exposition of the possible tools to be used in a way that encouraged the debate about the usefulness of their employment; the criteria collected were analyzed and grouped to determine, based on the formula, the Concordance Criteria (1) if there was a community in the interviewees' position.

$C c=[1-(E n / E t)] 100$

Where:

In: number of unfavorable criteria

Et: total respondents

Source: Salgado (2016)

In the first year the results were unequal, the concordance criteria matched the range assumed to determine the unit in the opinions issued; Subsequently, there was a rising trend towards the usefulness of the proposed auxiliary tools, which encouraged their employment to be decided initially in master's courses and later in research for the qualification of students in training as music professionals. The results of the survey indicated that at first there was rejection of the use of the tools during the initial preparation of the students, subsequently, there was a growth in the values of the indicators that expressed acceptance from the appropriation of the tools and the help they offered in the first stage of the research process that consisted in defending their research design (protocol or project).

\section{Development of an idea}

The beginning of an investigative process is difficult especially for music students whose aspiration is musical interpretation or practice, so their preparation focuses on the development of skills for such performance. The student faces this when selecting the degree project as an evaluative criterion for the completion of their degree studies, for this option, the writing of a thesis or thesis is usually required, and their defense.

It is at this time that ideas begin to be generated on the possible topics to be investigated, even without prior knowledge of what is written about it, or of the deficiencies, difficulties, or insufficient knowledge that persist in this regard.

The preparation depends on the initial orientation the student receives. For this, it is necessary to carry out a table work where you are offered information on the possible ways to identify their sources; The study of what has been written about this initial idea will be indicated, exploring and detecting aspects that have not yet been developed with sufficient clarity, or those that motivate you to strive to complete the process, which contributes to making a decision on the subject to be investigated.

In $80 \%$ of the cases that such guidance has been received, the defense of the issue has been satisfactory, and although there is always a factor of indecision given by the nerves of a first evaluation for the completion of their studies, the argument has prevailed and the justification of the decision taken.

Information for initial preparation can be obtained from books, interviews, magazine articles, defended theses, project results, from online social networks, among many other sources; But, in this case, there is a correlation between exploration and uncertainty: the more students inquire, the more difficulties they have in shaping their idea. In the title of the thesis the result and the limits of the investigation are revealed, hence the convenience of a previous preparation before it is stated. It must be brief, striking and synthesize the content of the thesis, as it is the first information the reader receives. As written from a scientific discipline it is important to use the terms or categories of it. 
A variant that helps in the formulation of the degree is the use of auxiliary tools that, as learning techniques, facilitate the procedure for the enunciation of the title and the elaboration of the research design. The first tool that we offer the student in our activities is the research portfolio (it constitutes the adaptation of the teaching portfolio to the research process); It is offered in this place since it facilitates the organization of the documentation that is obtained in the first moments and makes the signing more viable within the referential

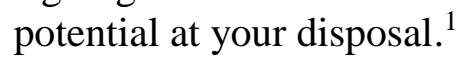

In the portfolio folders are created according to the classification that is easier to understand by the student, their interests or objectives; in them the bibliography, the cards or the references on the location of the sources and archives with commentaries on their contents can be saved. The number of folders in a portfolio is not regulated, however, sometimes its performance depends on the fulfillment of a task in which case, in general, teachers propose their amount and denomination. The organization of the folders can take various forms, the most used is by the location of the sources (it was used in more than $60 \%$ of the cases studied). A variant of the use of the research portfolio is shown in Figure 1; This portfolio was made from the keywords in the initial idea for the title statement.

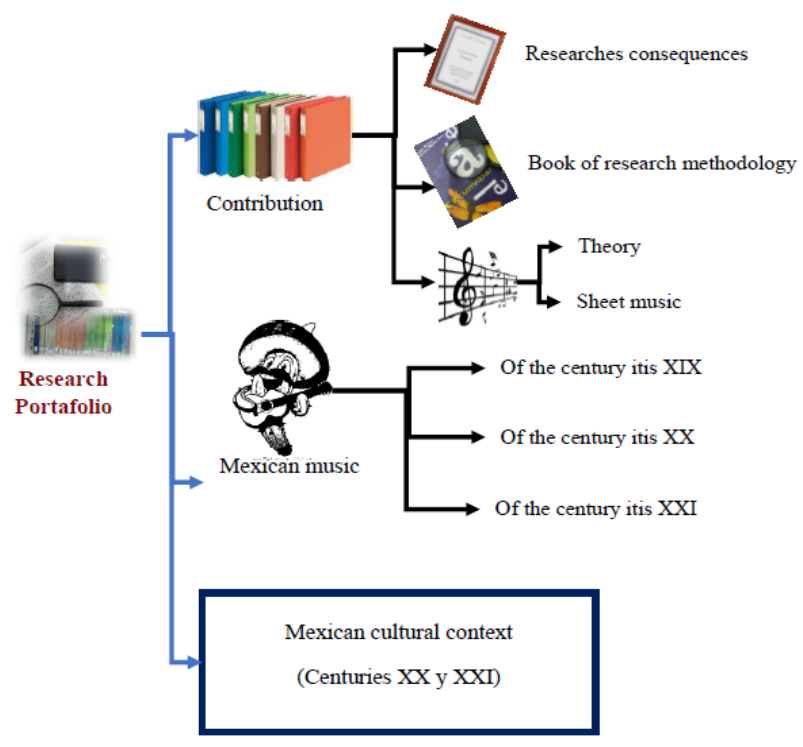

Figure 1 Portfolio variant based on the key words of the idea of the thesis title Source: Self Made

\footnotetext{
1 For the signing there are several digital tools bibliographic reference managers - with which you can automate the process and the settlement of the thesis: Endnote, Zotero, BibMe, EasyBib, Canva; all available on the internet.
}

In the portfolio, in addition to the elaborated files, you can include all the references that are in digital format, the comments and the location of the sources.

A positive experience is the contrast of various sources before assuming a position, such comparison helps the discrimination of practices or theories, and decision making, in this sense, the use of the portfolio favors the procedure; likewise, if they are organized by research stages, when the thesis is formed, -in case there is any doubt-, the sources compared can be easily accessed.

Another aspect in which the portfolio offers help is in the selection of information sources; The probability of access today is so great that despite the diversity and quantity available to everyone, it can cause errors related to its reliability, visibility in the organization of the sources also contributes to the observation of electronic addresses and sites where information is obtained.

Another tool that benefits the process in its beginnings is the mind map, in that sense, it serves as an auxiliary in the precision of what you want to investigate with which you can outline the idea of the title.

The mental map is a technique that provokes the analysis based on the graphic representation of what the researcher thinks, in this case attending to the key words present in the idea of the title; the map offers a global vision of the edges (converted into branches) to which each concept exposed in it influences.

The scheme that is generated during its elaboration is motivating from the figures, symbols, colors (optional) and typology of the lines that are used (figure 2), it starts by placing the idea of the theme of the center of the sheet where the ramifications arise according to the researcher's thinking. 


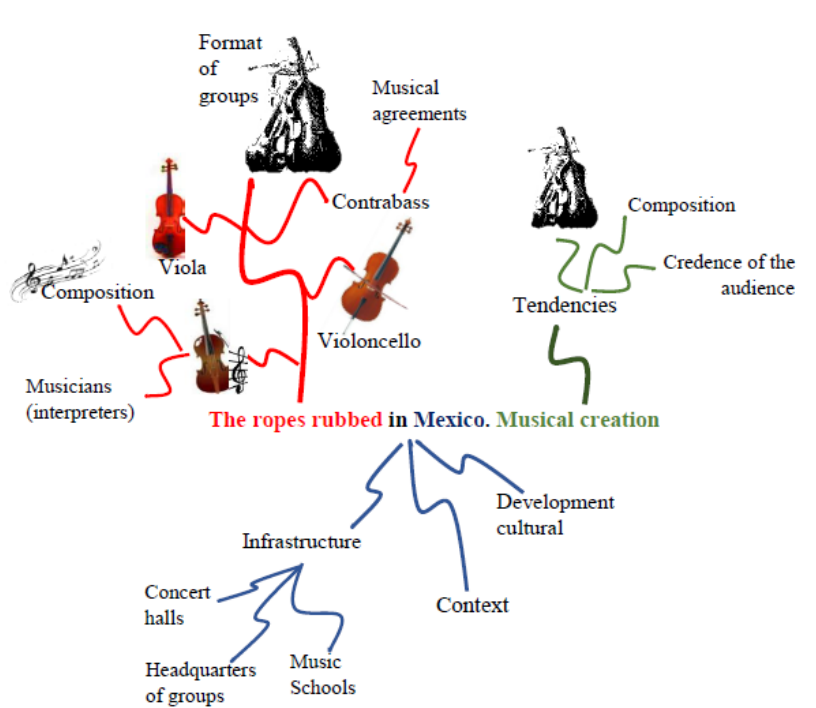

Figure 2 Example of a mind map on a topic idea Source: Self Made

The analysis is carried out externally in search of possible ramifications that can be found from the aspects that are related to each keyword. The representation of each secondary idea is made in the form of a branch that, in turn, opens towards others, according to the amount of new ideas related to the previous one; There are no limits to the number of branches, however, it should be borne in mind that, if the branching is very extensive on a single concept, the original idea should be rethought. Its usefulness helps determine the limits of research and the accuracy of the object to study.

The technique facilitates the grouping of ideas, their organization and the visibility of the dynamics that research can have from the connections found.

In the survey of teachers during the last two years of the study, it was the tool mostly valued as positive for their use at this stage of the research, depending on the accuracy of the thesis title (93.33\% of grades between 4 and 5); The reasons for such an estimate focused on the identification of the possible path that would be traveled from each key word (concept), the visibility of the aspects that would have the greatest weight in the investigation, and the possibility of changing the order of ideas on the knowledge base apprehended. Likewise, there is a tendency towards the increase of the quantity of four and five regarding the qualifications of two and three points in the following years (figure 3) consequence of the results experienced for the accuracy of the title, taking into account the references studied from the branching done.

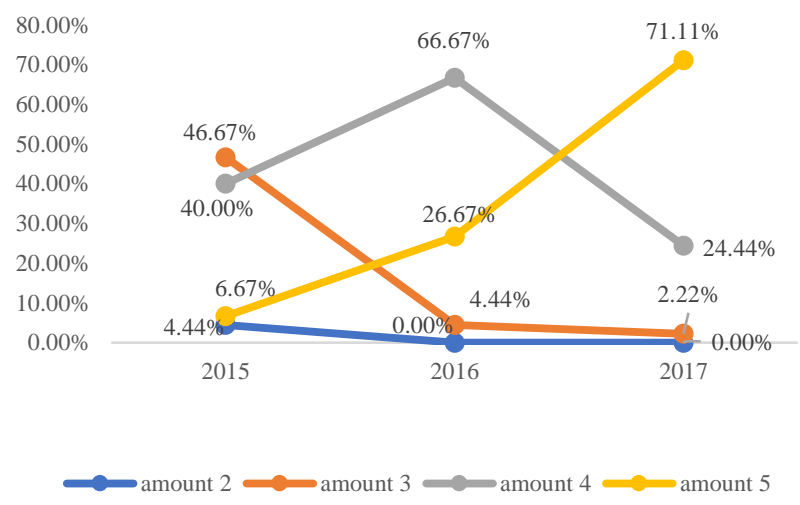

Figure 3 Qualifications granted to the use of the mental map for the accuracy of the thesis title Source: Self Made

Another experience in the application of the mind map was the repeated reading of the materials available to the students, a first familiarization reading and, later, a second one, emphasizing aspects related to the concepts or keywords identified in the initial idea, all of which generated new points of view and comments added to the research portfolio, which delimited the theoretical nuclei in correspondence with the interests, preparation and possibilities of the students.

Once the theoretical nuclei have been identified, and in order to conclude the topic statement and the elaboration of the research design or protocol, a new auxiliary tool can be used: the conceptual maps.

This tool helps to gain clarity in the meaning of the concepts also through a graphic representation that facilitates the learning, ordering and identification of significant links; Figure 4 shows a conceptual map that synthesizes in a very elementary way the meaning of the concept of music according to the definition offered by an encyclopedic dictionary of music (Lathan, 2008), the Royal Spanish Academy (RAE, 2018), and two etymological dictionaries (Deficiona, 2019; Music, 2019). 


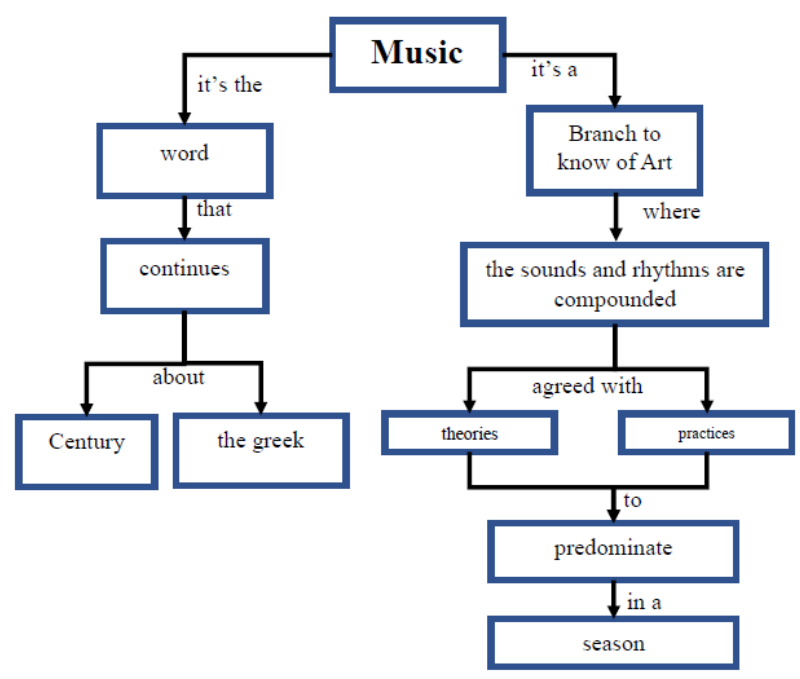

Figure 4 Example of a concept map. Source: Self Made

In the concept map the definition of the concept is distinguished, unlike the mental map, where the line of thought is located which, related to a concept, can guide the edge from which the study of an object, process, phenomenon, will be conducted, or subject.

The possibility of hierarchical ordering of concepts, taking into account the relationship between them, facilitates the visibility of the definition in its entirety and the grouping of meanings as a result of the contrast of sources.

The most explored sources for the defense of the subject were mainly defended thesis, articles published in scientific journals and research methodology books.

With the tools used, the study of the theoretical nuclei that formed the initial idea was facilitated, which was the starting point in many cases to identify the deficiencies and recommendations that remained from previous research to shape the title of the thesis and elaborate the design Of the investigation.

Although debate persists on the need to develop a research design, project or protocol; for the defense of the subject of the thesis, aspects included in them are required; Although it is something regulated in most universities, its validity must be considered, since the design favors the general orientation of the process. The aspects that are reiterated in the guidelines for the elaboration of the research design or protocol are the situation that generates the problem, its justification, the typology of the methods, and the results that are expected to be achieved.
In general, when the initial idea of the design is conformed and the previous study is carried out for the statement of the thesis title, a situation that demands the intervention of a researcher is used, which, together with the deficiencies of the theory and / or identified practices, and the legal basis that requires the defense of the subject to start the titling process, constitute the reason for the investigation; that is, the necessary argument for its justification. This starts the analysis for the formulation of the scientific problem. The determination of the problem is directly related to the title and / or subject of the thesis and for its formulation the theory focused on the areas of knowledge is taken as a basis, previously analyzed with the help of the tools - conceptual map, mental map, portfolio, or others in correspondence with the student's knowledge and level of preparation.

Research design in some way constitutes a requirement in the process, however, it is a guide for its realization; During its elaboration, the context in which the initial idea is located is characterized and the study of the categories and concepts of the scientific discipline from which the problematic situation is investigated and defined taking into account the deficiencies, contradictions or difficulties identified in the previous study.

If the results of this study offer links to other phenomena or objects studied and some information about the impact that the subject has had on society, the justification of the research becomes more truthful and stimulates the conduct of the study on the initial idea that is is profiling. However, there are criteria that research in arts does not require an initial design, it is proposed that part of something that is considered exciting, lacking rules; in this way they avoid the "(...) limitations of a problem posed in a biased way (...) and of the rigid methodological requirements (...)" (LópezCano, and San Cristóbal, 2014, p. 70). In this sense, the diversity of criteria enriches the process of scientific research in any area of knowledge; However, it is important not to underestimate what has so far been investigated or offers a reference on the selected idea, regardless of whether the subjective element plays a predominant role in the first stage of the investigation. In addition, it should be borne in mind that its starting point is an idea that is outlined for the formation of the thesis title and the design, protocol, project or research guide. 
With the information obtained from the study carried out, we are in a position to formulate the scientific problem whose response will provide the final elements for the title statement; that is, of the possible variants for its solution, one is chosen which will be the one that requires the title of the investigation.

For the formulation of the problem, the technique of decomposition of problems into subproblems can be used as an auxiliary tool; This tool is based on the procedure of the analytical method, that is, the decomposition of the whole into its parts, and allows independent observation of the components of the problem; this does not constitute a scientific method.

(...) what is called today "scientific method" is no longer a list of recipes to find the correct answers to the scientific questions, but the set of procedures by which a) the scientific problems arise and $b)$ are put to Test the scientific hypotheses. (Bunge, 2016, p. 46)

Figure 5 shows an example of the decomposition of the problem into subproblems, made from the study for a degree project and the table work prepared with the student in the 20172018 academic year.

\section{The problem scientist}

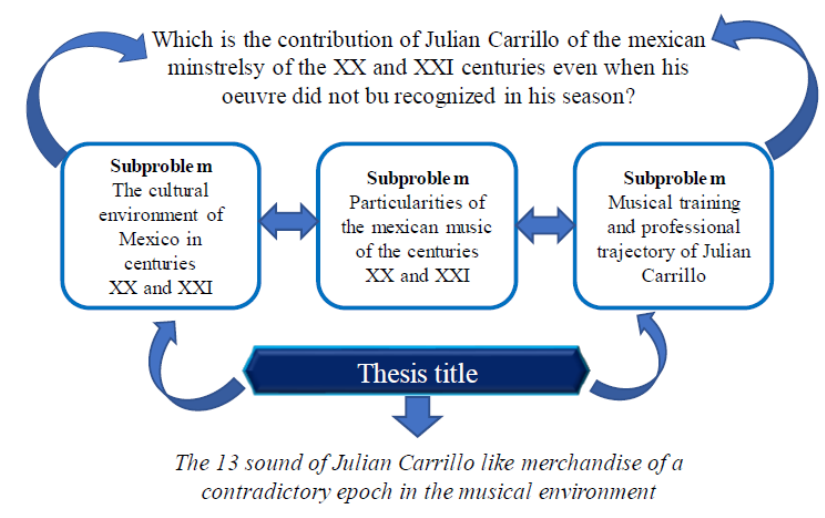

Figure 5 Use of the problem decomposition technique in subproblems to specify the research title

Source: Own elaboration based on the table work for Mejía (2018)

Due to its complexity, it was the least accepted technique, Figure 6 shows the percentage of qualifications awarded with values between four and five, according to the approval for employment at the beginning of the investigation $(62.22 \%)$.

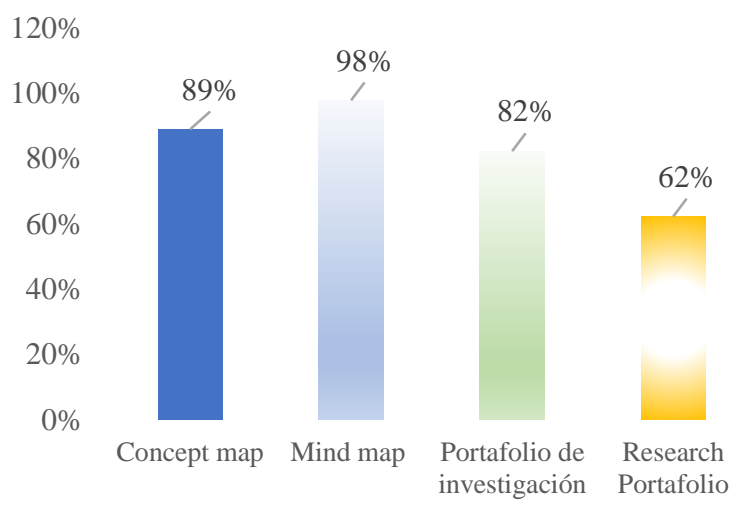

Figure 6 Percentage of grades awarded with values between 4 and 5

Source: Self Made

As experience in its application, during the table work between the tutor and the student, in some cases the reformulation of the thesis title was oriented according to the interests that the students pursued and the information provided, the use of categories and concepts that best fit the scientific discipline from which the research takes place.

\section{Conclusions}

The beginning of the research process as a degree project in students who are trained as music professionals is laborious and complex, taking into account that their preparation throughout the career is focused on a high quality performer; when it is decided to face this project, the generation of ideas that agglomerate above all due to the immediacy of the temporary requirements from the institutional regulations begins.

Specifying the idea for the title of the thesis transits through a different reading whose information is collected to the extent that there is access to the various sources; The organization of this process is faster and more visible when auxiliary tools such as the research portfolio are used. The conformation of the title of the thesis, given its characteristics, is preceded by a study that reveals the pretext or reason of the investigation, encloses the criteria on the idea generated of the title and the design of the research, the deficiencies or insufficiencies that persist and The scientific problem to solve. The diversity of edges from which this study can be approached, requires the help of tools that help in the organization, the apprehension of the meanings and the determination of the path by which it is going to travel. 
As a result of the document analysis, the unstructured interview and the applied survey, it was determined that the auxiliary tools that could be used in the initial stage of the research process for the degree project, depending on the accuracy of the thesis title and the Development of the research design were: the mental map, the conceptual map and the decomposition of the problem into subproblems, which, gradually, were welcomed by teachers and students.

\section{References}

Bunge, M. (2016). La ciencia, su método y su filosofía. México: Editorial Sudamericana. Nueva Imagen, colectivo editorial.

Deficiona (2019). Deficiona. Definición y etimología. Obtenido de https://deficiona.com>musica.

Lathan, A. (2008). Diccionario enciclopédico de la música. México: Fondo de Cultura Económica.

López- Cano, R.; y San Cristóbal, Ú. (2014). Investigación artística en música. Problemas, métodos, experiencias y modelos. Barcelona: ICM-ESMUC.

Música (2019). Etimología de la música. Obtenido de http://etimologías.dechile.net.

Mejía, C. (2018). El sonido 13 de Julián Carrillo como producto de una época controversial en el panorama musical. Zacatecas, México: Unidad Académica de Artes. Universidad Autónoma de Zacatecas "Francisco García Salinas".

Real Academia Española. (2018). Diccionario de la lengua española. Ed. Tricentenario. Obtenido de https://dle.es

Salgado, M. (2016). Modelo de gestión de la capacitación para una entidad en aprendizaje permanente. Matanzas: Universidad de Matanzas "Camilo Cienfuegos"

\section{Annex 1}

\section{Poll}

Evaluation of the use of auxiliary tools during the realization of the research design and formulation of the thesis title
Dear teacher (researcher):

A study is being carried out on the possibility of using tools that help the beginning of the research process for the academic qualification of music students; For this reason we ask for your opinion in this regard, taking into account the experience you have had in the orientation and defense of research designs (projects, protocols). Your criteria will be very useful to know if this procedure is possible or helps the process of preparing students for that moment. We thank you in advance for your participation and we apologize for any inconvenience this exercise may cause you.

\section{Personal information}

Mark with a cross or complete as appropriate.

- Exercises as: Teacher Researcher

Teacher-researcher

Other (state it)

- Years in the teaching exercise

- He has done the teaching exercise in: Degree studies (professional training) Masters , Training of doctors

- He has been a thesis tutor in:

Degree studies___ Master's degree Doctorate

\section{2. $\quad$ For exercise}

Please read each question carefully before answering.

2.1 On the title of the thesis, according to your experience in the pedagogical process for the training of the professional musician and during the preparation of the students for your degree project, mark with an $\mathrm{X}$ the place you consider correct (the 5 corresponds to the highest score ).

\begin{tabular}{|l|l|l|l|l|l|l|}
\hline No. & \multicolumn{1}{|c|}{ Indicator } \\
\hline 1. & $\begin{array}{l}\text { The thesis title proposal is } \\
\text { formulated from a } \\
\text { discussion in the } \\
\text { department or in the } \\
\text { academic body. }\end{array}$ & & & & & \\
\hline 2. & $\begin{array}{l}\text { The formulation of the } \\
\text { thesis title is done from a } \\
\text { table work between the } \\
\text { student, tutor and teacher. }\end{array}$ & & & & & \\
\hline 3. & $\begin{array}{l}\text { The title of the thesis is } \\
\text { chosen between the } \\
\text { student and the tutor }\end{array}$ & & & & & \\
\hline 4. & $\begin{array}{l}\text { The student presents the } \\
\text { thesis title proposal to the } \\
\text { tutor. }\end{array}$ & & & & & \\
\hline
\end{tabular}

JUAN-CARVAJAL, Mara Lioba. The title of the thesis in the professional training of the musician. Auxiliary tools. Journal of Teaching and Educational Research. 2019. 


\begin{tabular}{|c|c|}
\hline 5. & $\begin{array}{l}\text { To enunciate the degree, } \\
\text { the student is oriented to a } \\
\text { previous preparation } \\
\text { where the problems that } \\
\text { could be addressed are } \\
\text { revealed. }\end{array}$ \\
\hline 6. & $\begin{array}{l}\text { To propose the title of the } \\
\text { thesis the student is } \\
\text { oriented to the use of } \\
\text { auxiliary tools such as } \\
\text { mental or conceptual } \\
\text { maps, among others, that } \\
\text { help in their accuracy. }\end{array}$ \\
\hline
\end{tabular}

2.2 On the usefulness of the use of auxiliary tools for the preparation of students during the initial stage of their research and with the objective of stating the title of the thesis. Mark with an X the place you consider according to your criteria.

\begin{tabular}{|c|c|c|c|c|c|c|c|}
\hline No. & Indicator & 5 & 4 & 3 & 2 & 1 & Indicator \\
\hline 1. & $\begin{array}{l}\text { The use of the } \\
\text { concept map } \\
\text { facilitates the } \\
\text { formulation of } \\
\text { the thesis title. }\end{array}$ & & & & & & $\begin{array}{l}\text { The use of the } \\
\text { concept map } \\
\text { makes the } \\
\text { formulation of } \\
\text { the thesis title } \\
\text { more } \\
\text { cumbersome. }\end{array}$ \\
\hline 2. & $\begin{array}{l}\text { The use of the } \\
\text { mind map } \\
\text { enables the } \\
\text { accuracy of } \\
\text { the title. }\end{array}$ & & & & & & $\begin{array}{l}\text { The use of the } \\
\text { mind map } \\
\text { makes the } \\
\text { accuracy of } \\
\text { the title } \\
\text { difficult. }\end{array}$ \\
\hline 3. & $\begin{array}{l}\text { The use of the } \\
\text { teaching } \\
\text { portfolio helps } \\
\text { to organize the } \\
\text { work with the } \\
\text { bibliography } \\
\text { to support the } \\
\text { defense of the } \\
\text { subject }\end{array}$ & & & & & & $\begin{array}{l}\text { The use of the } \\
\text { teaching } \\
\text { portfolio } \\
\text { hinders the } \\
\text { organization } \\
\text { of work with } \\
\text { the } \\
\text { bibliography } \\
\text { to support the } \\
\text { defense of the } \\
\text { subject }\end{array}$ \\
\hline 4. & $\begin{array}{l}\text { The } \\
\text { decomposition } \\
\text { of the problem } \\
\text { that is } \\
\text { manifested in } \\
\text { the title, in } \\
\text { subproblems, } \\
\text { helps decision } \\
\text { making to } \\
\text { formulate the } \\
\text { final title of } \\
\text { the thesis. }\end{array}$ & & & & & & $\begin{array}{l}\text { The } \\
\text { decomposition } \\
\text { of the problem } \\
\text { that is } \\
\text { manifested in } \\
\text { the title, in } \\
\text { subproblems, } \\
\text { makes the } \\
\text { decision to } \\
\text { formulate the } \\
\text { final title of } \\
\text { the thesis } \\
\text { more } \\
\text { imprecise. }\end{array}$ \\
\hline
\end{tabular}

